\title{
Influência de diferentes extratos aquosos de plantas medicinais no desenvolvimento de Colletotrichum gloeosporioides e de Fusarium moniliforme
}

MARCONDES, M.M.; MARTINS MARCONDES, M.; BALDIN, I.; MAIA, A.J.; LEITE, C.D.; FARIA, C.M.D.R.* Departamento de Agronomia, Universidade Estadual do Centro Oeste (UNICENTRO). Rua Simeão Varela de Sá, 03, CEP 85040-080. Guarapuava-PR, Brasil. *cfaria@unicentro.br

RESUMO: O objetivo deste trabalho foi avaliar a influência dos extratos aquosos das plantas medicinais alecrim, alho, cravo-da-índia, sálvia, capim-limão, orégano ou pimenta-do-reino no desenvolvimento in vitro de Colletotrichum gloeosporioides e de Fusarium moniliforme. Os extratos foram obtidos pela infusão de $60 \mathrm{~g}$ de cada planta medicinal em $200 \mathrm{~mL}$ de água fervente. Cada extrato aquoso foi fracionado em concentrações de 0, 5, 10 e $20 \%$ (p:v) e incorporado ao meio de cultivo BDA (batata-dextrose-ágar) antes da esterilização em autoclave. Posteriormente, um disco de $8 \mathrm{~mm}$ de diâmetro de micélio fúngico de cada patógeno foi transferido para o centro de placas de Petri. Após 24, 48 e 96 horas de incubação em câmara de crescimento a $22 \pm 2{ }^{\circ} \mathrm{C}$ e fotoperíodo de 12 horas avaliou-se o crescimento micelial de $F$. moniliforme e de C. gloesporioides. No último período de incubação, também se quantificou o número de conídios de cada fungo. Para o teste de germinação adicionou-se nas cavidades de placas de teste Elisa, uma alíquota de $40 \mu \mathrm{L}$ de cada extrato nas concentrações de 0,5 , 10 e $20 \%$, e outra alíquota, da suspensão de conídios de cada patógeno. Após 24 horas a $22 \pm 2{ }^{\circ} \mathrm{C}$, no escuro, a germinação dos conídios foi paralisada com a adição de $20 \mu \mathrm{L}$ de lactofenol; avaliou-se então a porcentagem de germinação de conídios. Os experimentos foram conduzidos no delineamento inteiramente casualizado em esquema fatorial $7 \times 4$ (extratos de plantas medicinais $x$ concentrações) com quatro repetições. Para ambos os patógenos o extrato aquoso de alho e cravo-da-índia apresentaram maior ou total inibição do crescimento micelial, respectivamente, quando comparado com os demais extratos. Para C. gloeosporioides, o extrato de cravo-da-índia apresentou menor número de conídios em todas as concentrações testadas, e para o extrato de alho a $20 \%$, também não foi observada a germinação de conídios. O extrato de alho foi eficiente em reduzir o número e a germinação dos conídios de $F$. moniliforme na concentração de $20 \%$. Os extratos de alecrim, cravo-da-índia, orégano e pimenta-do-reino, nas maiores concentrações, tiveram efeito positivo na redução da produção de conídios deste mesmo fungo.

Palavras-chave: controle alternativo, fungos patogênicos, agricultura orgânica.

ABSTRACT: Influence of different aqueous extracts of medicinal plants in the development of Colletotrichum gloeosporioides and Fusarium moniliforme. The objective of this study was to evaluate the influence of aqueous extracts of the medicinal plants rosemary, garlic, clove, sage, lemongrass, oregano and black pepper in the in vitro development of Colletotrichum gloeosporioides and Fusarium moniliforme. The extracts were obtained by infusing $60 \mathrm{~g}$ of each medicinal plant in $200 \mathrm{~mL}$ of boiling water. Each aqueous extract was fractionated in the concentrations of 0, 5, 10 and 20\% (w:v) and incorporated into the PDA (potato dextrose agar) culture medium before sterilization by autoclaving. Later, an $8 \mathrm{~mm}$ diameter disc of each pathogen mycelium was transferred to the center of the Petri dishes. After 24, 48 and 96 hours of incubation in a growth chamber at $22 \pm 2{ }^{\circ} \mathrm{C}$ and a photoperiod of 12 hours, we evaluated the mycelial growth of $F$. moniliforme, and C. gloesporioides. In the last period of incubation, we quantified the production of conidia of each fungus. For the germination test, we added, into the wells of an ELISA test plates, a $40 \mu \mathrm{L}$ aliquot of each extract at the concentrations of $0,5,10$ and $20 \%$ and another aliquot of a suspension of conidia of each pathogen. After 24 hours at $22 \pm 2{ }^{\circ} \mathrm{C}$ in the dark, the germination of the fungi was stopped with the addition of $20 \mu \mathrm{L}$ of lactophenol. Then, we evaluated the germination of conidia. The experiments 
followed a completely randomized $7 \times 4$ factorial design (medicinal plants $\times$ concentrations) with four replications. For both pathogens, the aqueous extract of garlic and clove showed a greater or total inhibition of the mycelial growth, when compared to the other extracts. For the C. gloeosporioides, the clove extract showed a lower number of conidia at all concentrations tested, and the garlic extract at $20 \%$ showed not conidial germination. The garlic extract was efficient to reduce the conidial number and germination of $F$. moniliforme at $20 \%$. Extracts of rosemary, clove, oregano and black pepper, in the highest concentrations, had positive effect in reducing the production of spores of the same fungus.

Key words: alternative control, pathogenic fungi, organic agriculture.

\section{INTRODUÇÃO}

A preocupação com o meio ambiente e com a segurança alimentar tem levado as pessoas a questionarem a agricultura moderna, aumentando a demanda pela produção orgânica que preconiza, entre outros, a preservação dos agroecossistemas por meio do uso adequado dos recursos naturais e obtenção de alimentos de melhor qualidade sem perder a produtividade (Schifferstein \& Oude Ophuis, 1998). O controle de doenças causadas por fungos em larga escala é feito, geralmente, com fungicidas que podem causar dano ao meio ambiente e à saúde humana.

Considerando este fato, faz-se necessária a utilização de métodos alternativos no controle de doenças. Dentre os métodos, as substâncias bioativas presentes em plantas ou fungos (compostos secundários, fitocomplexos, óleos essenciais, entre outros), podem desempenhar funções importantes nas interações planta-patógeno, seja pela ação antimicrobiana direta, seja por ativar mecanismos de defesa das plantas que venham a ser tratadas com esses compostos (Bonaldo et al., 2005).

Bonaldo et al. (2004) observou que extrato de Eucaliptus citriodora quando aplicado 72, 48 e 24 horas antes da inoculação de Colletotrichum lagenarium em pepino, reduziu o número e o tamanho das lesões. Extratos de Piper longum foram capazes de reduzir a severidade e a incidência dos fungos Pyricularia oryzae, Rhizoctonia solani, Botrytis cinerea, Phytophthora infestans, Puccinia recondita e Erysiphe graminis (Lee et al., 2001). Extratos de casca de maçã e semente de mamão reduziram a incidência de Colletotrichum gloeosporioides em pós-colheita de mamão (Bautista-Banõs et al., 2003). Extrato de Sargassum filipendula, em várias concentrações, inibiu o crescimento fúngico de Aspergillus niger, A. flavus, A. parasiticus, Penicillium sp. e Fusarium oxysporum (Martinez-Lozano et al., 2000).

Neste sentido, o objetivo do trabalho foi avaliar o potencial dos extratos aquosos de plantas medicinais, tais como: alecrim, alho, capim-limão, cravo-da-índia, orégano, pimenta-do-reino e sálvia, no desenvolvimento in vitro de Colletotrichum gloeosporioides e Fusarium moniliforme.

\section{MATERIAL E MÉTODOS}

Os experimentos foram conduzidos no Laboratório de Fitopatologia do Departamento de Agronomia da Universidade Estadual do CentroOeste, campus CEDETEG, em Guarapuava - PR. A partir de fruto de maçã com sintoma característico de antracnose (Colletotrichum gloeosporioides) e de sementes de milho naturalmente infectados, em condições de campo, com Fusarium moniliforme, realizou-se $O$ isolamento direto dos fungos para meio de batata-dextrose-ágar (BDA). A partir de culturas puras dos fungos foram obtidas culturas monospóricas e, estas, foram mantidas à temperatura de $7 \pm 2{ }^{\circ} \mathrm{C}$ junto à coleção micológica do laboratório.

Preparou-se, individualmente, o extrato aquoso por meio de infusão durante 15 minutos, de 60 $\mathrm{g}$ de: bulbilhos de alho (Allium sativum L.); de botões florais de cravo-da-índia (Caryophillus aromaticus L.); de folhas secas de alecrim (Rosmarinus officinalis L.); de capim-limão (Cymbopogon citratus (DC) Stapf); de orégano (Origanum vulgare L.); de sálvia (Salvia officinalis L.); e de sementes de pimenta-do-reino (Piper nigrum L.), todos obtidos no comércio. Os extratos foram fracionados nas concentrações de 5, 10 e 20\% (p:v) e adicionados em meio de cultura BDA (batata-dextrose-ágar), exceto nos tratamentos testemunha (concentração $0 \%$, onde foi utilizado somente o meio BDA. Em seguida, os mesmos foram esterilizados em autoclave durante 20 minutos a $120^{\circ} \mathrm{C}$, sob pressão de $1,1 \mathrm{kgf} \mathrm{cm}^{-2}$, e vertidos em placas de Petri de 7 $\mathrm{cm}$ de diâmetro. Após a solidificação dos meios com os extratos efetuou-se a repicagem de um disco de $8 \mathrm{~mm}$ de diâmetro, contendo micélio fúngico dos respectivos isolados fúngicos com idade de 10 dias. As placas foram incubadas em câmara de crescimento a $22 \pm 2{ }^{\circ} \mathrm{C}$ sob fotoperíodo de 12 horas. As avaliações do crescimento micelial foram realizadas às 24, 48 e 96 horas de incubação, com auxílio de paquímetro, fazendo-se medições do diâmetro das colônias (média de duas medidas diametralmente opostas da colônia), utilizando-se como referência uma linha reproduzida na placa no primeiro período de avaliação. O diâmetro total 
da colônia foi calculado em relação ao crescimento micelial final obtido com a colonização dos fungos na placa do tratamento testemunha.

No último período de avaliação (96 horas) realizou-se a quantificação de conídios de $C$. gloeosporioides e F. moniliforme adicionando-se 5 $\mathrm{mL}$ de água destilada contendo Tween $(0,5 \%)$ sobre o crescimento micelial das colônias de cada fungo, raspando-os com uma alça de Drigalski esterilizada, durante 15 segundos. Desta suspensão, pipetouse $20 \mu \mathrm{L}$ para uma câmara de Neubauer para a quantificação de conídios dos respectivos fungos, em microscópio óptico com aumento de 400 vezes.

Para verificar a influência das plantas medicinais na germinação de conídios de $C$. gloeosporioides e F. moniliforme, prepararamse os extratos aquosos conforme descrito no experimento anterior, utilizando as mesmas plantas medicinais, armazenadas em temperatura ambiente. Adicionou-se uma alíquota de $40 \mu \mathrm{L}$ da suspensão $10^{6}$ conídios $\mathrm{mL}^{-1}$ de cada patógeno, individualmente, em cavidades de placas de ELISA. $\mathrm{Na}$ sequência, pipetaram-se mais $40 \mu \mathrm{L}$ de cada extrato, individualmente, nas concentrações de 0 , 10, 20 e 40\%, de forma a se obter as concentrações finais de $0,5,10$ e $20 \%$, em cada cavidade da placa, distribuídas em quatro repetições. As placas ELISA foram mantidas em câmara úmida em $B O D$ à 22 ${ }^{\circ} \mathrm{C} \pm 2{ }^{\circ} \mathrm{C}$, no escuro, durante 24 horas. Após esse período, efetuou-se a paralisação da germinação dos conídios com a adição de $20 \mu \mathrm{L}$ de lactofenol
(Regente et al., 1997). A avaliação foi realizada por meio da contagem de 100 conídios por repetição em microscópio ótico com aumento de 400 vezes. Foram considerados conídios germinados quando o comprimento do tubo germinativo atingiu, pelo menos, $1 / 3$ do diâmetro do conídio.

$O$ delineamento experimental utilizado foi inteiramente casualizado em esquema fatorial $7 \mathrm{x}$ 4 (plantas medicinais $x$ concentrações) com quatro repetições. Os resultados obtidos foram submetidos à análise de variância e quando significativos analisados a regressão polinomial para a variável concentração dos extratos e aplicado o teste de Tukey $(P \leq 0,05)$ para os extratos por meio do programa estatístico SISVAR (Ferreira, 2008).

\section{RESULTADOS E DISCUSSÃO}

Para este experimento houve efeito significativo $(P \leq 0,05)$ entre os extratos aquosos (Tabela 1) e entre as doses avaliadas sob o crescimento micelial de Colletotrichum gloesosporioides (Figura 1). Observou-se a ação antifúngica dos extratos aquosos de alecrim, alho, capim-limão, cravoda-índia, orégano, pimenta-do-reino e sálvia pelo menor crescimento micelial do fungo na presença dos extratos em relação ao tratamento testemunha (concentração 0\%) (Figura 1).

No crescimento micelial de $C$. gloeosporioides a equação ajustada foi quadrática em função das concentrações crescentes $(0,5$,

TABELA 1. Efeito de diferentes extratos aquosos em concentrações crescentes no crescimento micelial $(\mathrm{cm})$ de Colletotrichum gloeosporioides após 24, 48 e 96 horas de incubação.

\begin{tabular}{|c|c|c|c|c|c|c|c|c|c|c|c|c|c|c|c|c|c|c|c|c|c|c|}
\hline \multirow{4}{*}{ Extrato } & \multicolumn{22}{|l|}{ Período } \\
\hline & \multicolumn{7}{|l|}{24 horas } & \multicolumn{7}{|c|}{48 horas } & \multicolumn{8}{|l|}{96 horas } \\
\hline & \multicolumn{22}{|c|}{ Concentração (\%) } \\
\hline & 0 & \multicolumn{2}{|l|}{5} & \multicolumn{2}{|l|}{10} & \multicolumn{2}{|l|}{20} & \multicolumn{2}{|l|}{0} & \multicolumn{2}{|l|}{5} & 10 & \multicolumn{2}{|l|}{20} & 0 & \multicolumn{2}{|c|}{5} & \multicolumn{2}{|l|}{10} & \multicolumn{2}{|c|}{20} & \\
\hline Alecrim & $1,94 e^{*}$ & 1,71 & $\mathrm{C}$ & 1,56 & $\mathrm{~b}$ & 1,48 & $\mathrm{~d}$ & 3,59 & $E$ & 3,38 & de & $3,18 d$ & 3,00 & d & 4,94 & $\mathrm{bc}$ & 4,86 & $\mathrm{~cd}$ & 4,62 & c & 4,38 & $d$ \\
\hline Alho & $1,66 \quad b$ & 1,46 & $b$ & 0,98 & $\mathrm{a}$ & 0,00 & a & 3,18 & $\mathrm{bc}$ & 2,71 & $\mathrm{~b}$ & $2,13 \quad b$ & 0,00 & a & 4,76 & $\mathrm{bc}$ & 4,07 & $b$ & 3,48 & $\mathrm{~b}$ & 0,00 & a \\
\hline Capim-limão & $1,85 \mathrm{de}$ & 1,83 & $\mathrm{~d}$ & 1,81 & $\mathrm{c}$ & 1,70 & e & 3,50 & de & 3,55 & e & 3,49 e & 3,35 & e & 5,01 & c & 5,18 & e & 5,10 & $\mathrm{~d}$ & 4,93 & e \\
\hline Cravo-da-Índia & $1,70 \mathrm{bc}$ & 1,35 & $a$ & 1,00 & a & 0,90 & $b$ & 3,08 & $a b$ & 2,35 & a & $1,21 \quad a$ & 0,90 & $b$ & 4,70 & $a b$ & 3,46 & a & 1,95 & a & 0,90 & $\mathrm{~b}$ \\
\hline Orégano & $1,70 \quad b c$ & 1,64 & $\mathrm{C}$ & 1,51 & $\mathrm{~b}$ & 1,34 & $\mathrm{c}$ & 3,33 & $\mathrm{~cd}$ & 3,35 & c & $3,11 \mathrm{~cd}$ & 2,61 & $c$ & 4,94 & $\mathrm{bc}$ & 4,95 & de & 4,55 & C & 3,81 & c \\
\hline Pimenta-do-reino & 1,55 a & 1,48 & $\mathrm{~b}$ & 1,00 & $\mathrm{a}$ & 1,35 & $\mathrm{c}$ & 2,95 & $A$ & 2,98 & $\mathrm{C}$ & $3,00 \mathrm{c}$ & 2,61 & $c$ & 4,45 & a & 4,59 & $\mathrm{C}$ & 4,48 & $\mathrm{C}$ & 3,90 & C \\
\hline Sálvia & $1,78 \mathrm{~cd}$ & 1,71 & $\mathrm{C}$ & 1,57 & $\mathrm{~b}$ & 1,51 & $d$ & 3,40 & $\mathrm{D}$ & 3,36 & $d$ & $3,06 \mathrm{~cd}$ & 2,27 & c & 5,01 & $\mathrm{C}$ & 4,87 & d & 4,43 & $\mathrm{C}$ & 3,93 & $\mathrm{C}$ \\
\hline $\mathrm{CV}(\%)$ & 3,20 & & & & & & & 2,88 & & & & & & & 3,06 & & & & & & & \\
\hline Fc extr. & 508,33 & & & & & & & 958,1 & & & & & & & 757,54 & & & & & & & \\
\hline Fc dose & 717,15 & & & & & & & 1031 & & & & & & & 977,55 & & & & & & & \\
\hline Fc extr. $x$ doses & 109,59 & & & & & & & 162,9 & & & & & & & 164,00 & & & & & & & \\
\hline
\end{tabular}

*Médias seguidas de mesma letra na coluna não diferem significativamente entre si pelo teste de Tukey a $5 \%$ de probabilidade.

Rev. Bras. PI. Med., Campinas, v.16, n.4, p.896-904, 2014. 
10 e $20 \%$ ) nos períodos de avaliação de 24, 48 e 96 horas para os diferentes extratos, exceto para os extratos de capim-limão, pimenta-do-reino e sálvia no período de 24 horas, para o alecrim nos períodos de 48 e 96 horas e para o cravo-da-índia

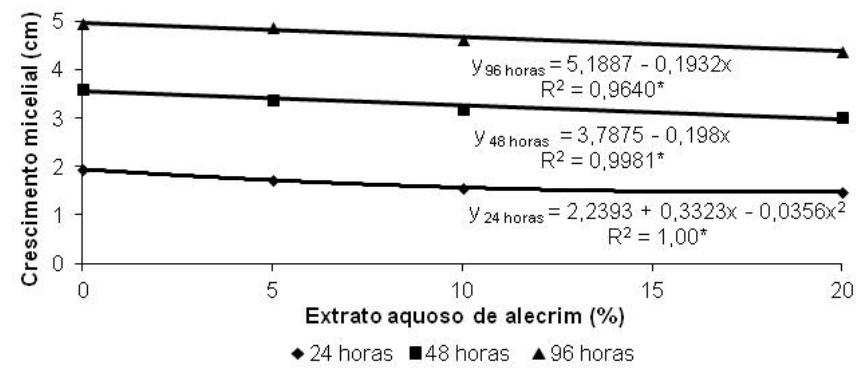

A

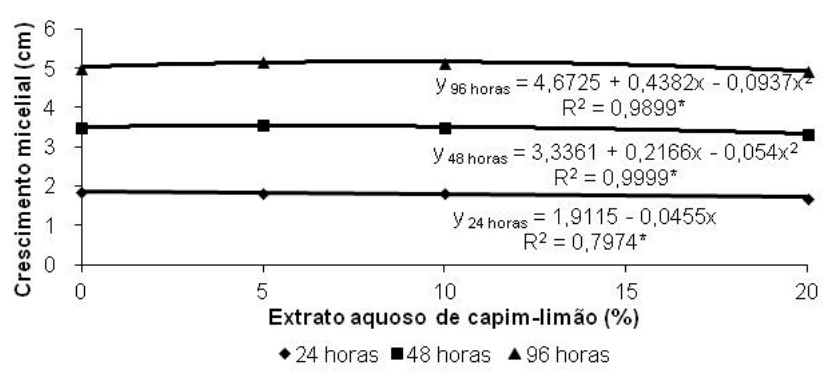

C

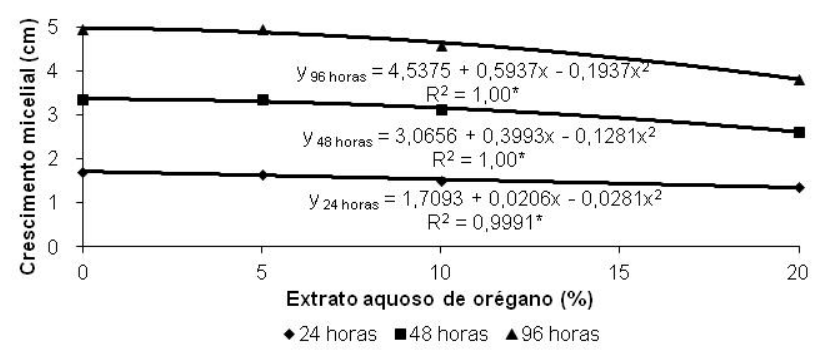

E

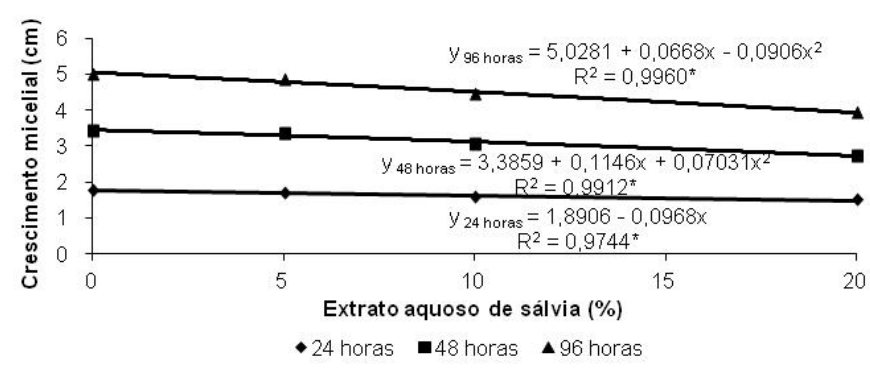

G no período de 96 horas que apresentaram efeito linear decrescente (Figura 1).

Destaca-se, na concentração de $20 \%$, o extrato de alho (Figura 1B) que inibiu totalmente o desenvolvimento do patógeno e o de cravo-da-

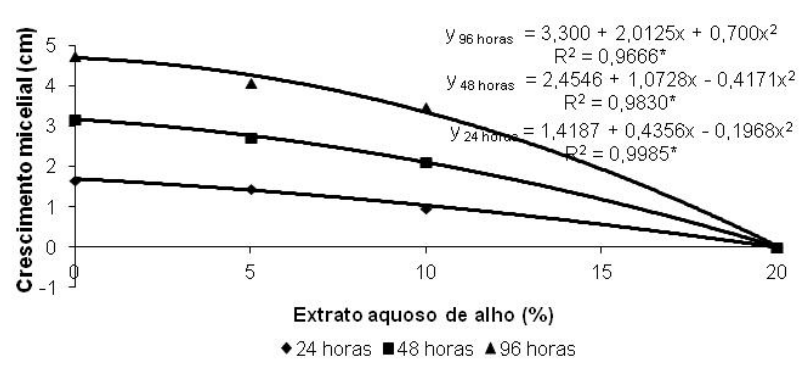

B

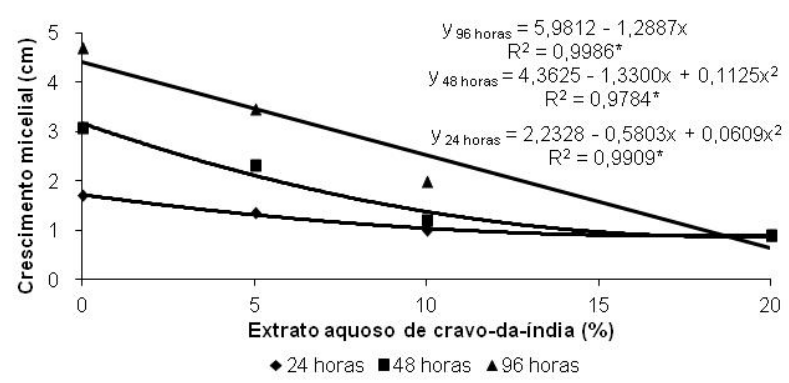

D

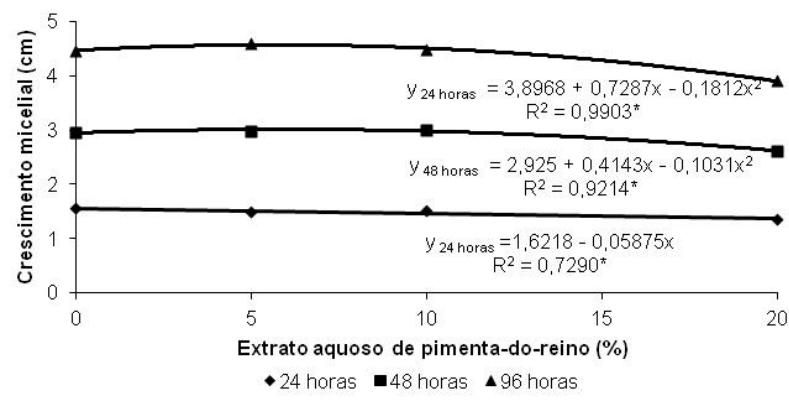

$\mathbf{F}$

FIGURA 1. Crescimento micelial $(\mathrm{cm})$ de Colletotrichum gloeosporioides submetido às concentrações de $0,5,10$ e $20 \%$ dos extratos aquosos de A) alecrim; B) alho; C) capim-limão; D) cravo-da-índia; E) orégano; F) pimentado-reino e G) sálvia, após 24, 48 e 96 horas de incubação a $22 \pm 2{ }^{\circ} \mathrm{C}$ e fotoperíodo de 12 horas. *significativo a $1 \%$ de probabilidade. 
índia, que apresentou crescimento micelial de apenas $0,9 \mathrm{~cm}$ após 96 horas de incubação (Figura 1D). Os resultados obtidos foram semelhantes aos de Rozwalka et al. (2008) que, avaliando o efeito fungitóxico de plantas medicinais e aromáticas, no crescimento micelial de Glomerella cingulata (Colletotrichum gloeosporioides) verificaram que o extrato aquoso de cravo-da-índia na concentração de $10 \%$ inibiu totalmente o crescimento do patógeno.

Para o extrato de alecrim observou-se efeito quadrático após 24 horas de incubação, sendo que a concentração de $20 \%$ inibiu em $23,7 \%$ o crescimento deste fungo em relação à testemunha. Também foi verificado efeito linear decrescente na concentração de $20 \%$ após 48 e 96 horas de incubação, entretanto as respectivas porcentagens de inibição de $16,4 \%$ e $11,3 \%$ foram menores quando comparada à primeira avaliação (Figura 1A).

Verificou-se efeito quadrático para o extrato de orégano nos três períodos de avaliação, sendo observada redução de 21,2; 21,6 e 22,9\% no crescimento micelial, em relação à testemunha, respectivamente, nos períodos de 24, 48 e 96 horas após a incubação (Figura 1E). Para o extrato de sálvia observou-se efeito linear decrescente no período de 24 horas e quadrático para os períodos de 48 e 96 horas, com redução de 15,2; 33,2 e $21,6 \%$, respectivamente, em relação à testemunha (Figura 1G). Romero et al. (2012) observaram que o óleo essencial de orégano em concentrações acima de $500 \mathrm{ppm}$ promoveram a total inibição do crescimento micelial e da germinação de esporos de C. gloeosporioides, e que a concentração de 250 ppm inibiu em $73,95 \%$ e $33,58 \%$ o crescimento micelial de F. moniliforme e C. gloeosporioides, respectivamente.

Quanto à produção de conídios de $C$. gloeosporioides, o extrato aquoso de cravo-daíndia apresentou menor produção na concentração de $10 \%$ dentre todos os extratos avaliados e, na concentração de $20 \%$ tanto o extrato de cravo-daíndia quanto o extrato de alho promoveram inibição total na formação de conídios. Já para o extrato aquoso de capim-limão foi observado aumento no número de conídios em todas as doses quando comparado com os demais extratos (Tabela 2).

Para germinação de conídios de $C$. gloeosporioides o extrato de cravo-da-índia proporcionou a segunda maior porcentagem de germinação $(4,25 \%)$, na concentração de $10 \%$, não diferindo estatisticamente do extrato de capimlimão onde foi observada a maior porcentagem de conídios germinados $(11,0 \%)$. Nas concentrações de 5 e 20\% não houve diferença estatística entre todos os extratos avaliados (Tabela 2).

Foi observado efeito significativo $(p \leq 0,05)$ entre os extratos aquosos (Tabela 3 ) e entre as doses avaliadas (Figura 2), neste experimento, em relação ao crescimento micelial de Fusarium moniliforme. Observou-se a ação antifúngica de

TABELA 2. Produção de conídios $\left(10^{5} \mathrm{~mL}^{-1}\right)$ de Colletotrichum gloeosporioides submetido a concentrações crescentes de diferentes extratos aquosos de plantas medicinais após 96 horas de incubação a $22 \pm 2{ }^{\circ} \mathrm{C} \mathrm{e}$ fotoperíodo de 12 horas e germinação de conídios (\%) após 24 horas de incubação a $22 \pm 2^{\circ} \mathrm{C}$ no escuro.

\begin{tabular}{|c|c|c|c|c|c|c|c|c|c|c|c|c|c|c|c|c|}
\hline \multirow{3}{*}{ Extrato } & \multicolumn{8}{|c|}{ Produção de conídios $\left(10^{5} \mathrm{~mL}^{-1}\right)$} & \multicolumn{8}{|c|}{ Germinação de conídios (\%) } \\
\hline & \multicolumn{16}{|c|}{ Concentração (\%) } \\
\hline & 0 & & 5 & & 10 & & 20 & & 0 & & 5 & & 10 & & 20 & \\
\hline Alecrim & 14,12 & $a^{*}$ & 21,92 & $a b$ & 22,20 & $b$ & 21,10 & $\mathrm{~b}$ & 4,25 & a & 1,50 & a & 0,75 & a & 5,25 & a \\
\hline Alho & 30,20 & a & 65,30 & d & 41,10 & bc & 0,00 & a & 17,00 & $\mathrm{~b}$ & 0,00 & a & 0,00 & a & 0,25 & a \\
\hline Campim-limão & 25,15 & a & 71,12 & $d$ & 90,87 & $d$ & 131,10 & $d$ & 8,50 & a & 3,25 & a & 11,00 & $b$ & 1,00 & a \\
\hline Cravo-da-Índia & 23,17 & a & 6,87 & a & 1,70 & a & 0,00 & a & 18,00 & $\mathrm{~b}$ & 6,75 & a & 4,25 & $a b$ & 6,75 & a \\
\hline Orégano & 20,52 & $\mathrm{a}$ & 37,05 & $\mathrm{bc}$ & 34,35 & $b$ & 30,75 & $\mathrm{bc}$ & 8,00 & $a$ & 4,00 & a & 1,50 & a & 0,50 & a \\
\hline Pimenta-do-reino & 21,52 & a & 25,67 & $a b c$ & 53,50 & c & 34,65 & $\mathrm{bc}$ & 7,00 & a & 1,75 & a & 1,75 & a & 0,00 & a \\
\hline Sálvia & 18,25 & $\mathrm{a}$ & 41,82 & c & 36,40 & $\mathrm{bc}$ & 44,17 & $\mathrm{c}$ & 21,25 & $\mathrm{~b}$ & 4,00 & a & 0,00 & a & 0,25 & a \\
\hline CV (\%) & 15,48 & & & & & & & & 71,24 & & & & & & & \\
\hline Fc extr. & 385,25 & & & & & & & & 6,63 & & & & & & & \\
\hline Fc dose & 24,84 & & & & & & & & 50,24 & & & & & & & \\
\hline Fc extr. $x$ doses & 33,78 & & & & & & & & 5,43 & & & & & & & \\
\hline
\end{tabular}

*Médias seguidas de mesma letra na coluna não diferem significativamente entre si pelo teste de Tukey a $5 \%$ de probabilidade. Equações de regressão da variável concentrações versus produção de conídios de $C$. gloeosporioides: $\mathrm{y}_{\text {alho }}=-5,18+2,951 \mathrm{x}-7,052 \mathrm{x}^{2} / \mathrm{R}^{2}=0,9999^{*} ; \mathrm{y}_{\text {capim- }}$ ${ }_{\text {limāo }}=12,26+6,06 x / R^{2}=0,9650^{*} ; y_{\text {pimenta-do-reino }}=6,224-8,8359 x-1,3811 x^{2} / R^{2}=0,6083^{*}$. Equações de regressão da variável concentrações versus germinação: $\mathrm{y}_{\text {aleciim }}=11,43-8,83 x+1,81 x^{2} / R^{2}=0,9621^{*} ; y_{\text {alho }}=38,43-26,58 x+4,31 x^{2} / R^{2}=0,9347^{*} ; y_{\text {capim-limăo }}=6,7409+0,4059 x-0,033 x^{2} / R^{2}=0,4072^{*} ; y_{\text {crarlo }}$ da-india $=35,18-20,81 x+3,43 x^{2} / R^{2}=0,9938^{*} ; y_{\text {orégano }}=9,75-2,50 x / R^{2}=0,9328^{*} ; y_{\text {pimenta-do-reino }}=7,87-2,10 x / R^{2}=0,8013^{*} ; y_{\text {salvia }}=45-28,58 x+4,37 x^{2} / R^{2}=0,9867^{*}$. 
extratos aquosos de plantas pelo menor crescimento micelial de F. moniliforme na presença destes em relação ao tratamento testemunha (concentração 0\%) (Figura 2).

Para F. moniliforme verificou-se efeito quadrático no crescimento micelial em função das concentrações dos extratos de capim-limão, cravoda-índia, orégano e pimenta (Figura 2), sendo que o extrato de cravo-da-índia na concentração de $20 \%$ inibiu totalmente o crescimento deste fungo (Figura 2D). Quando se utilizou extrato aquoso de alho, obteve total inibição do crescimento micelial do fungo na concentração de $20 \%$ do extrato até 48 horas após a incubação, havendo crescimento micelial do fungo $(1,46 \mathrm{~cm})$ após esse período. (Figura $2 \mathrm{~B})$. Venturoso et al. (2010) estudando a influência de diferentes metodologias de esterilização sobre a atividade antifúngica de extratos aquosos de alho, canela e cravo-da-índia, verificaram que o extrato aquoso de cravo-da-índia proporcionou total inibição do crescimento micelial de Fusarium solani.

Fungos dos gêneros Curvularia e Alternaria também apresentaram menor desenvolvimento de colônia, com valores variáveis de 30 a $75 \%$, quando cultivados em meios contendo extrato de alho nas concentrações de 1.000 a $10.000 p p m$, respectivamente (Barros et al., 1995). No presente experimento, o extrato de orégano também se destacou por apresentar redução de 39,25; 52,2 e $56,5 \%$ no crescimento micelial deste fungo conforme o aumento no período de incubação (24, 48 e 96 horas) (Figura 2E). Observou-se resposta linear decrescente em função das concentrações do extrato aquoso de sálvia nos períodos de 24 , 48 e 96 horas, reduzindo em 22,8; 25,3 e 23,6\%, respectivamente, o crescimento micelial de $F$. moniliforme na concentração de $20 \%$ em relação à testemunha (Figura 2G).

No que se refere à produção de conídios de F. moniliforme, os extratos de alecrim, cravoda-índia, orégano e pimenta-do-reino foram os que apresentaram os menores valores em função das maiores concentrações (10 e 20\%) (Tabela 4). Ribeiro \& Bedendo (1999) relataram o efeito antifúngico do extrato aquoso de pimenta ao observarem a inibição de até $83,8 \%$ na produção de conídios de C. gloeosporioides, utilizando doses crescentes do extrato, entre 100 e 10000 ppm, acrescidas em meio BDA.

A germinação de conídios de F. moniliforme foi menor em todas as concentrações do extrato aquoso de alecrim $(0,5,10$ ou $20 \%)$, assim como o extrato de alho nas concentrações de 5 e $20 \%$, e de pimenta a $5 \%$ quando comparado a outros extratos (Tabela 4).

Nos resultados obtidos nas condições deste experimento, os extratos de alho e cravo-da-índia na concentração de $20 \%$ apresentaram maior potencial de inibição no crescimento micelial e produção de conídios de Colletotrichum gloeosporioides. Para

TABELA 3. Efeito de diferentes extratos aquosos em concentrações crescentes no crescimento micelial (cm) de Fusarium moniliforme após 24, 48 e 96 horas de incubação.

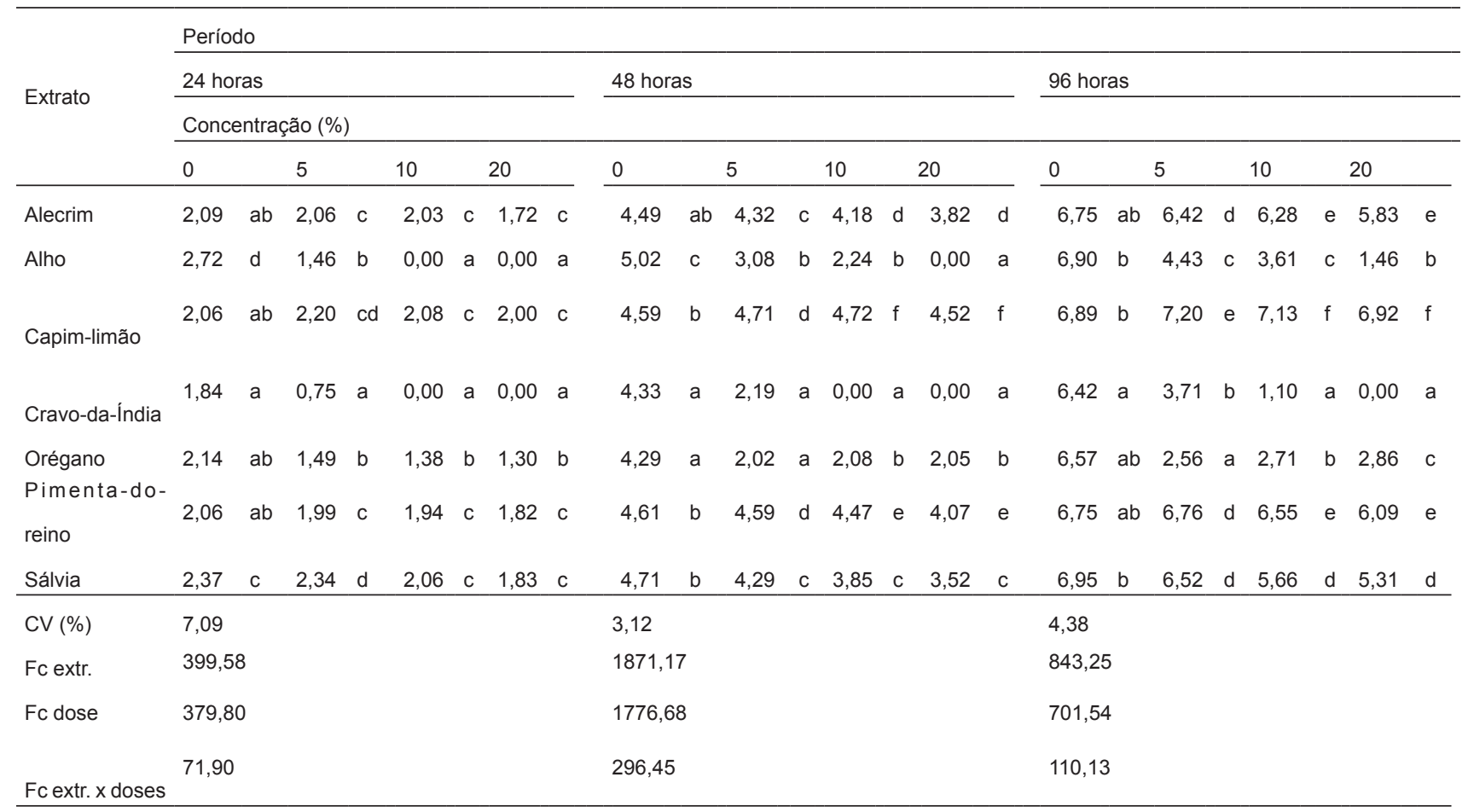

Médias seguidas de mesma letra na coluna não diferem significativamente entre si pelo teste de Tukey a $5 \%$ de probabilidade. 


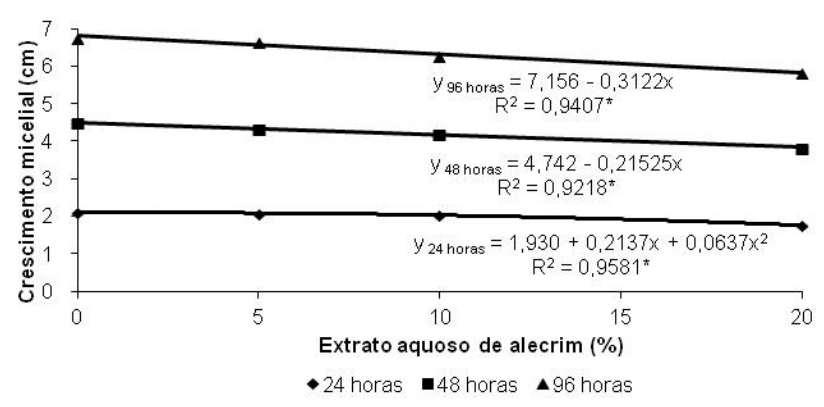

A

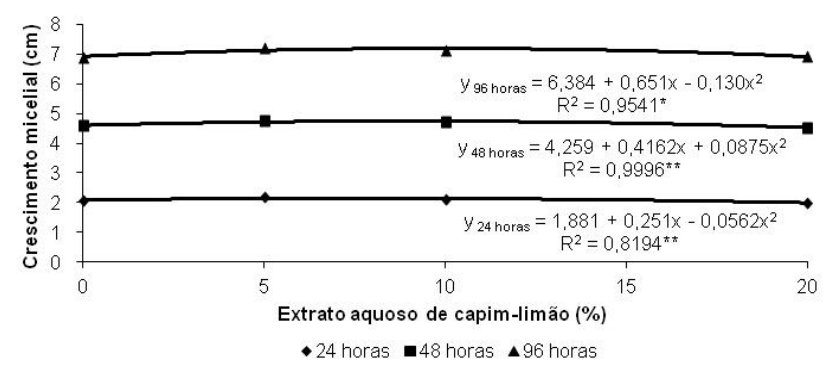

C

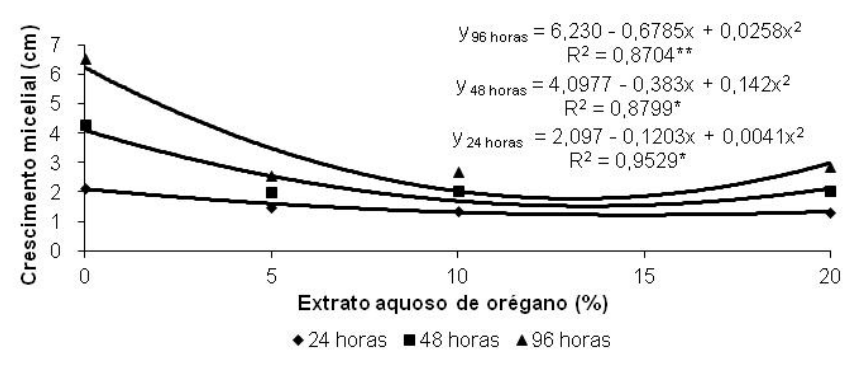

E

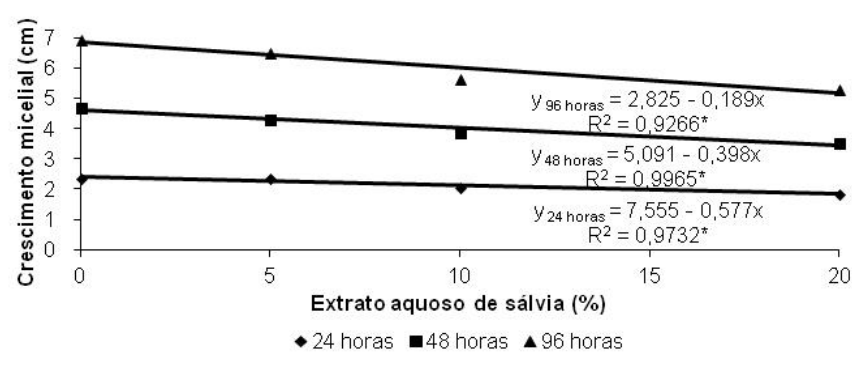

\section{G}

FIGURA 2. Crescimento micelial $(\mathrm{cm})$ de Fusarium moniliforme submetido às concentrações de $0,5,10$ e $20 \%$ dos extratos aquosos de A) alecrim; B) alho; C) capim-limão; D) cravo-da-índia; E) orégano; F) pimenta-do-reino e G) sálvia, após 24,48 e 96 horas de incubação a $22 \pm 2^{\circ} \mathrm{C}$ e fotoperíodo de 12 horas *significativo a $1 \%$ de probabilidade. " significativo a $5 \%$ de probabilidade.

o Fusarium moniliforme, o extrato de alho a $20 \%$ proporcionou inibição tanto no crescimento micelial quanto na produção e germinação de conídios. Os extratos de cravo e orégano nas concentrações de 10 e $20 \%$ também reduziram o crescimento

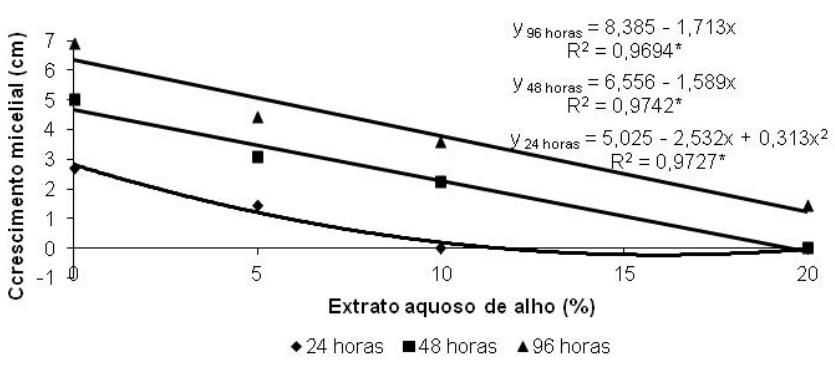

B

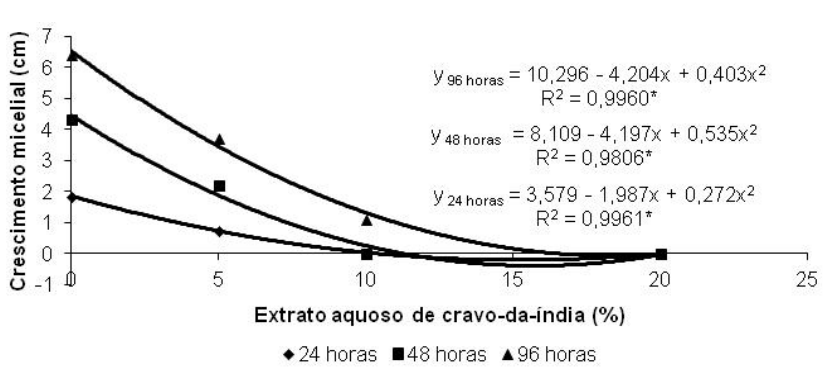

D

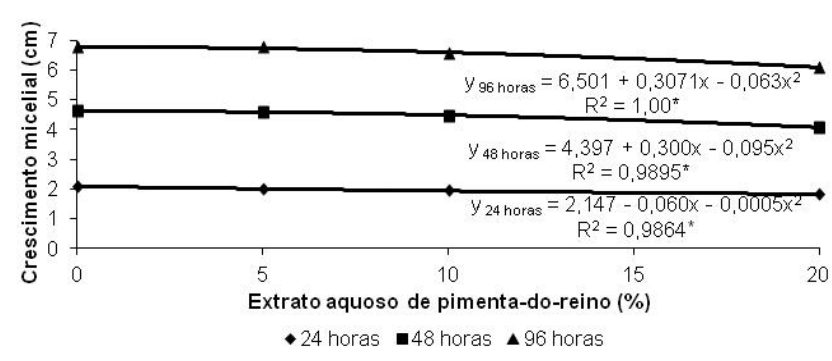

$\mathbf{F}$

Rev. Bras. PI. Med., Campinas, v.16, n.4, p.896-904, 2014. 
TABELA 4. Produção de conídios $\left(10^{4} \mathrm{~mL}^{-1}\right)$ de Fusarium moniliforme submetido a concentrações crescentes de diferentes extratos aquosos de plantas medicinais após 96 horas de incubação a $22 \pm 2{ }^{\circ} \mathrm{C}$ e fotoperíodo de 12 horas e germinação de conídios (\%) após 24 horas de incubação a $22 \pm 2^{\circ} \mathrm{C}$ no escuro.

\begin{tabular}{|c|c|c|c|c|c|c|c|c|c|c|c|c|c|c|c|c|}
\hline \multirow{3}{*}{ Extrato } & \multicolumn{8}{|c|}{ Produção de conídios $\left(10^{4} \mathrm{~mL}^{-1}\right)$} & \multicolumn{8}{|c|}{ Germinação de conídios (\%) } \\
\hline & \multicolumn{16}{|c|}{ Concentração (\%) } \\
\hline & 0 & & 5 & & 10 & & 20 & & 0 & & 5 & & 10 & & 20 & \\
\hline Alecrim & 0,18 & $a b^{*}$ & 0,13 & a & 0,09 & $A$ & 0,10 & a & 2,00 & a & 0,25 & a & 0,25 & a & 1,00 & a \\
\hline Alho & 0,14 & a & 0,22 & bc & 0,25 & $\mathrm{~B}$ & 0,08 & a & 22,00 & $b$ & 1,50 & a & 1,00 & $a b$ & 0,00 & a \\
\hline Campim-limão & 0,25 & $\mathrm{~b}$ & 0,28 & c & 0,33 & bc & 0,51 & c & 14,50 & $a b$ & 18,25 & $\mathrm{bc}$ & 59,00 & $d$ & 64,25 & c \\
\hline Cravo-da-índia & 0,18 & $a b$ & 0,15 & $\mathrm{bc}$ & 0,13 & $A$ & 0,09 & a & 4,00 & $a$ & 21,00 & c & 18,00 & c & 26,50 & $b$ \\
\hline Orégano & 0,25 & $\mathrm{~b}$ & 0,15 & bc & 0,16 & $A$ & 0,16 & a & - & & - & & - & & - & \\
\hline Pimenta-do-reino & 0,16 & $a$ & 0,12 & a & 0,15 & $A$ & 0,15 & a & 2,50 & $a$ & 0,75 & a & 3,75 & $a b c$ & 14,00 & $a b$ \\
\hline Sálvia & 0,10 & a & 0,20 & $a b c$ & 0,35 & $\mathrm{C}$ & 0,42 & $\mathrm{~b}$ & 10,00 & $a b$ & 6,25 & $a b$ & 15,50 & $\mathrm{bc}$ & 13,75 & $a b$ \\
\hline CV (\%) & \multicolumn{8}{|c|}{19,89} & \multicolumn{8}{|c|}{52,85} \\
\hline Fc extr. & \multicolumn{8}{|c|}{68,67} & \multicolumn{8}{|c|}{61,30} \\
\hline Fc dose & \multicolumn{8}{|c|}{8,133} & \multicolumn{8}{|c|}{15,73} \\
\hline Fc extr. $x$ doses & \multicolumn{8}{|c|}{18,661} & \multicolumn{8}{|c|}{12,11} \\
\hline
\end{tabular}

*Médias seguidas de mesma letra na coluna não diferem significativamente entre si pelo teste de Tukey a $5 \%$ de probabilidade. Equações de regressão da variável concentrações versus produção de conídios de $F$. moniliforme: $\mathrm{y}_{\text {alecrim }}=0,1937-0,273 x / R^{2}=0,7339^{*} ; y_{\text {alho }}=-0,1023+0,2943 x-$ $0,0615 x^{2} / R^{2}=0,9391^{*} ; y_{\text {capim-limäo }}=0,332-0,113 x+0,00392 x^{2} / R^{2}=0,9865^{*} ; y_{\text {cravo-da-india }}=0,202-0,0261 x / R^{2}=0,9644^{*} ; y_{\text {orégano }}=0,361-0,1472 x-0,0248 x^{2} /$ $\mathrm{R}^{2}=0,9178^{*} ; \mathrm{y}_{\text {salvia }}=-0,1059+0,112 x / \mathrm{R}^{2}=0,9915^{*}$. Equações de regressão da variável concentrações versus germinação: $\mathrm{y}_{\text {alho }}=47,687-$ $31,887 x+5,062 x^{2} / R^{2}=0,9249^{*} ; y_{\text {capim-limäo }}=-8,50+19,0 x / R^{2}=0,8727^{*} ; y_{\text {cravo-da-india }}=1,250+6,45 x / R^{2}=0,7545^{*} ; y_{\text {pimenta-do-reino }}=-3,75+3,675 x / R^{2}=0,6733^{*}$.

No entanto, a partir dos resultados obtidos, experimentos em campo deverão ser realizados para possível indicação do uso dos extratos aquosos como mais uma opção na produção orgânica de produtos agrícolas.

\section{REFERÊNCIA}

BARROS, S.T.; OLIVEIRA, N.T. de; MAIA, L.C. Efeito do extrato de alho (Allium sativum) sobre o crescimento micelial de Curvularia spp e Alternaria spp. Summa Phytopathologica, v.21, n.2, p.168-170, 1995.

BAUTISTA-BAÑOS, S.; HERNÁNDEZ-LÓPEZ, M.; BOSQUEZ-MOLINA, E.; WILSON, C.L. Effects of chitosan and plant extracts on growth of Colletotrichum gloeosporioides, anthracnose levels and quality of papaya fruit. Crop Protection. v.22, n.9, p.1087-1092, 2003.

BONALDO, S.M. SCHWAN-ESTRADA, K.R.F.; STANGARLIN, J.R.; TESSMAN, D.J.; SCAPIM, C.A. Fungitoxicidade, atividade elicitora de fitoalexinas e proteção de pepino contra Colletotrichum lagenarium, pelo extrato aquoso de Eucalyptus citriodora. Fitopatologia Brasileira, v.29, n.2, p.128-134, 2004.

BONALDO, S.M.; PASCHOLATI, S.F., ROMEIRO, R.S. Indução de resistência: noções básicas e perspectivas. In: CAVALCANTI, L.S.; DI PIERO, R.M.; CIA, P.; PASCHOLATI, S.F.; RESENDE, M.L.V.; ROMEIRO, R.S. Indução de resistência em plantas a patógenos e insetos. Piracicaba: FEALQ, 2005, p.11-28.

FERREIRA, D.F. SISVAR: um programa para análises e ensino de estatística. Revista Cientifíca Symposium,
Lavras, v.6, n.2, p.36-41, 2008.

LEE, S.E.; PARK, B.S.; KIM, M.K.; CHOI, W.S.; KIM, H.T.; CHO, K.Y.; LEE, S.G.; LEE, H.S. Fungicidal activity of pipernonaline a piperidine alkaloid derived from long pepper Piper longum L. against phytopathogenic fungi. Crop Protection, Oxford, v.20, n.6, p.523-528, 2001.

MARTINEZ-LOZANO, S.J.; GARCIA, S.; HEREDIA, N.; VILLARREAL-RIVERA, L.; GARCIA-PADILLA, C.A. Antifungal activity of extracts of Sargassum filipendula. Phyton- International Journal of Experimental Botany, v.66, p.179-182, 2000.

REGENTE, M.C.; OLIVA, C.R.; FELDMAN, M.L.; CASTAGNARO, A.P.; LA CANAL, L. de. Sunflower leaf antifungal peptide active against Sclerotinia sclerotiorum. Physiologia Plantarum, Sweden, v.100, n.11, p.178-182, 1997.

RIBEIRO, L.F.; BEDENDO, I.P. Efeito inibitório de extratos vegetais sobre Colletotrichum gloeosporioides - agente causal da podridão de frutos de mamoeiro. Scientia Agricola, v.56, n.4, p.1267-1271, 1999. (Suplemento)

ROMERO, A.L.; ROMERO, R.B.; SILVA, E.L.; DINIZ, S.P.S.S.; OLIVEIRA, R.R.; VIDA, J.B. Composição química e atividade do óleo essencial de Origanum vulgare sobre fungos fitopatogênicos. UNOPAR Científica Ciências Biológicas e da Saúde, v.14, n.4, p.231-235, 2012.

ROZWALKA, L.C.; LIMA, M.R.L.Z.C.; MIO, L.L.M.; NAKASHIMA, T. Extratos, decoctos e óleos essenciais de plantas medicinais e aromáticas na inibição de Glomerella cingulata e Colletotrichum gloeosporioides de frutos de goiaba. Ciência Rural, v.38, n.2, p.301307, 2008. 
SCHIFFERSTEIN, H.N.J.; OUDE OPHUIS, P.A.M. Healthrelated determinants of organic food consumption in the Netherlands. Food Quality and Preference, v.9, n.3, p.119-133, 1998.

VENTUROSO, L.R.; BACCHI, L.M.A.; GAVASSONI,
W.L.; PONTIM, B.C.A.; CONUS, L.A. Influencia de diferentes metodologias de esterilização sobre atividade antifúngica de extratos aquosos de plantas medicinais. Revista Brasileira de Plantas Medicinais, v.12, n.4, p.499-505, 2010. 